\title{
BMJ Open The association between macronutrient intake and cognition in individuals aged under 65 in China: a cross- sectional study
}

\author{
Bingjie Ding, ${ }^{1}$ Rong Xiao, ${ }^{2}$ Weiwei Ma, ${ }^{2}$ Lei Zhao, ${ }^{3}$ Yanxia Bi, ${ }^{1}$ Yong Zhang ${ }^{4}$
}

To cite: Ding B, Xiao R, Ma W, et al. The association between macronutrient intake and cognition in individuals aged under 65 in China: a crosssectional study. BMJ Open 2018:8:e018573. doi:10.1136/ bmjopen-2017-018573

- Prepublication history for this paper is available online. To view these files, please visit the journal online (http://dx.doi org/10.1136/bmjopen-2017018573).

Received 8 July 2017

Revised 28 November 2017

Accepted 28 November 2017

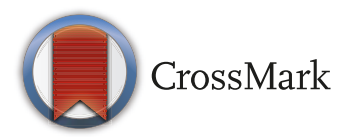

1Department of Clinical Nutrition, Beijing Friendship Hospital, Capital Medical University,

Beijing, China

${ }^{2}$ School of Public Health, Beijing Key Laboratory of Environmental Toxicology, Capital Medical University, Beijing, China ${ }^{3}$ Department of Molecular Physiology and Biophysics, Holden Comprehensive Cancer Center, University of lowa Carver College of Medicine, lowa, USA

${ }^{4}$ Department of Chronic Disease, Daxing Centre for Disease Control and Prevention, Beijing, China

Correspondence to

Prof. Rong Xiao;

xiaor1222@163.com and Dr

Weiwei Ma;

zibeikeweiwei@163.com

\section{ABSTRACT}

Objective The aim of this retrospective study was to explore the correlation between daily energy intake from macronutrients and cognitive functions in a Chinese population aged less than 65 years.

Design This is a cross-sectional study to explore the relationships between macronutrients' intake and cognitive function. The analysis of variance (ANOVA) and $\chi^{2}$ test were used to compare the demographic and physical characteristics, lifestyle and laboratory parameters with the intake of macronutrients among different quartiles of $\%$ fat/energy. Multivariate logistic regression analysis was applied to identify the potential risk factors of mild cognitive impairment (MCl).

Participants Young and middle-aged participants (age $<65$ years) were recruited from Beijing, China. The Montreal cognitive assessment (MoCA) and minimental state examination (MMSE) were used to evaluate the cognitive functions, and the dietary intake of the participants was estimated with a semi-quantitative food frequency questionnaire (FFQ).

Results Among the 661 participants, 80 (12.1\%) had $\mathrm{MCl}$, while $581(87.9 \%)$ had normal cognitive functions. On evaluating the data based on the age group, educational background, and conditions of hyperlipidaemia and total energy intake, the results revealed that high \% fat (upper quartile: adjusted OR (aOR) 3.90, 95\% Cl1.53 to 9.89 , $\mathrm{P}=0.004$ ), and high \% protein intake (upper quartile: aOR $2.77,95 \% \mathrm{Cl} 1.24$ to 6.15 ) were greatly associated with increased frequency of $\mathrm{MCl}$, while high \% carbohydrate intake (upper quartile: aOR0.30, $95 \% \mathrm{Cl} 0.12$ to 0.72 ) was correlated with decreased prevalence of $\mathrm{MCl}$.

Conclusion The dietary pattern with high percentage of energy intake from fat and protein, and low-energy intake from carbohydrate might have been associated with cognitive decline in a Chinese population under 65 years of age.

\section{INTRODUCTION}

Macronutrients including fat, protein and carbohydrates are the main sources of dietary energy, and a high-energy intake may increase the risk of cognitive impairment. Dietary pattern and intake of nutrients have been shown to be associated with cognitive
Strengths and limitations of this study

- This study is a cross-sectional study to explore the intake of macronutrients in the diet and cognition in Chinese people.

- Compared with the previously published studies, this study involved relatively younger participants aged less than 65 years to minimise the influence of age on cognition.

- The Montreal cognitive assessment (MoCA) and mini-mental state examination (MMSE) were both employed to evaluate the cognitive functions of participants.

- The limitation of this study was that there was no report on the breakdown of dietary fat consumption because different sources of fat that may have different effects on cognition.

functions. ${ }^{12}$ Mediterranean diet (MD), rich in fresh vegetables, fruit, fish and olive oil, has been reported to have associations with good cognitive performance. ${ }^{3} 4$ Similarly, two earlier studies of our research group have previously demonstrated that a diet rich in marine products, fruit, vegetables and vegetable juice could prevent cognitive decline in the elderly population. ${ }^{15}$ Moreover, it was demonstrated that the long-chain omega-3 fatty acids (LC-n3-FA) and polyphenols including resveratrol and curcuminand flavonoids from these diets are likely to be the main nutrients beneficial to cognitive function. ${ }^{4}{ }^{6}$ Some previous studies have reported that adequate dietary intake of vitamins and minerals were closely associated with decreased risk of cognitive impairment. ${ }^{7}$ However, those studies could examine only the cumulative effects of different foods and micronutrients, without considering the influence of energy intake and the source of energy as a possible risk factor in developing mild cognitive impairment (MCI). A prospective cohort study ${ }^{8}$ reported that high average energy consumption could increase the risk 
of cognitive impairment or dementia (OR:1.62, 95\% CI 1.25 to 2.10), after analysing factors such as micronutrients, vascular disease, diabetes, smoking, BP and BMI, but this study included the differential sources of energy intake.

The primary determinants of total calorific intake and the largest proportion of the components of any diet include the three types of macronutrients: carbohydrates, fat and protein. The balanced ratio of carbohydrates, fat and protein was the basis of healthy diets, which ensures adequate intake of all nutrients. Up to now, however, there were limited studies that investigated the significant effect of macronutrient (carbohydrates, fat and protein) with cognitive function. Roberts $e t a l^{9}$ have reported that a relatively high calorific intake from carbohydrates might increase the risk of MCI or dementia in elderly persons. Due to the inherent differences in Western and Chinese diets, this conclusion may not significantly apply to the Chinese population. Thus, we conducted a case-control study to explore the relationship between macronutrients and energy intake and cognitive functions in a cohort of the Chinese population less than 65 years of age to control the bias of ageing.

\section{METHODS}

\section{Participants}

This retrospective study was conducted in three community hospitals in Beijing, from 1 December 2015 to 30 September 2016. We identified 1197 (age <65) potentially eligible participants out of 4360 outpatients, and 777 among them agreed to participate $(64.9 \%$ response rate) in the study. Finally, 661 participants were included in the study according to the exclusion criteria: individuals with serious diseases (cancer, severe psychiatric disorders such as depression and schizophrenia, a recent history of heart or respiratory failure and chronic liver or renal failure, $\mathrm{n}=25$ ); individuals with conditions known to affect cognitive functions (a recent history of alcohol abuse, $n=43$; cerebral infarction, $n=27$; severe brain injury, $\mathrm{n}=3$ ); and individuals with Alzheimer's disease $(\mathrm{AD})(\mathrm{n}=0)$, Parkinson's disease $(\mathrm{PD})(\mathrm{n}=0)$ or long-term frequent intake of anti-depressants and other medications for neurological diseases $(n=18)$. All experimental procedures were conducted in accordance with the guidelines in the Declaration of Helsinki and approved by the Ethics Committee of Capital Medical University, Beijing (No.2014SY33). All participants signed a written informed consent and had the right to terminate their participation.

\section{Data collection and grouping}

A questionnaire including demographic characteristics and lifestyle was prepared and the data was collected and assessed by well-trained researchers by conducting faceto-face interviews. The collected data by questionnaire included age, gender, education, race/ethnicity (divided into Han and other, including Manchu, Hui, Koreans,
Mongols and so forth), work intensity, smoking (yes or no), drinking (yes or no), physical exercise and disease history (hypertension, diabetes and so forth). Height and weight were measured with height and weight scales (RGZ-120-RT, Wuxi weighing apparatus factory). Waist and hip circumferences were measured by flexible rulers, and waist-to-hip ratio (WHR) was calculated as waist circumference $(\mathrm{cm}) /$ hipcircumference. Blood samples were collected for quantifying the lipid levels (total cholesterol and triglyceride) with an auto-analyser (Olympus, AU 400, Japan). Hyperlipidaemia was defined as hypercholesterolaemia (serum cholesterol $>5.2 \mathrm{mmol} / \mathrm{L}$ ) and/or hypertriglyceridaemia (serum triglyceride $>1.7 \mathrm{mmol} / \mathrm{L}$ ).

Age was categorised into three groups: $<45$ years' old; $45-55$ years' old; and $>55$ years' old. Body mass index (BMI) was calculated as weight $(\mathrm{kg}) / \mathrm{height}^{2}\left(\mathrm{~m}^{2}\right)$ and subsequently divided into three groups: ${ }^{10} 11$ normal $\left(18.5-24.9 \mathrm{~kg} / \mathrm{m}^{2}\right)$; overweight $\left(25.0-29.9 \mathrm{~kg} / \mathrm{m}^{2}\right)$; and obese $\left(\geq 30 \mathrm{~kg} / \mathrm{m}^{2}\right)$. Educational levels were divided into three ranks: ${ }^{2} \leq 6$ years (illiterate and elementary school); 7-12 years (junior high school, senior high school and technical secondary school); and $>12$ years (college and graduate school). Work intensity, which was estimated based on their profession, was categorised into three groups: ${ }^{13}$ light ( $75 \%$ of time sitting or standing and $25 \%$ of time standing with activities, such as office workers, salespeople and teachers); moderate (25\% of time sitting or standing and $75 \%$ of time with special occupational activities, eg, students' daily activities, motor vehicle driving, metalworking and electrical installation); and heavy (40\% of time sitting or standing and $60 \%$ of time with special occupational activities, eg, gardening, weightbearing walking, dancing, skiing, riding a bicycle, mountain climbing, logging, manual excavation, and playing basketball and football). Aerobicexercise ${ }^{14}$ refers to physical exercise of low to high intensity, including running/ jogging, climbing, rope jumping, brisk walking, swimming and playing badminton.

\section{DIETARY QUESTIONNAIRE}

Dietary intake was estimated by using a semi-quantitative food frequency questionnaire (FFQ) ${ }^{715}$ which included a total of 34 items (whole grain, red meat, pork, beef, mutton, chicken, fish, vegetables and vegetable products, milk, eggs, fruit and vegetables, nuts, sugared beverages, cooking oil, etc), consumption frequency (daily, weekly, monthly, yearly or never) and the quantity of each item consumed. The quantity of food consumed was estimated using food models and measuring rulers or cups. Subsequently, the intake of nutrients per day was calculated based on the China Food Composition Database. ${ }^{16}$ Trained dietary interviewers helped all participants in completing the FFQ to ensure the accuracy of the collected data.

\section{Cognitive function screening for $\mathrm{MCl}$}

The Montreal cognitive assessment (MoCA) and minimental state examination (MMSE) were employed to 
evaluate the cognitive functions of participants according to the standard protocols. The total scores of MoCA was 30 and the cut-off for screening MCI was 13 for illiterate individuals, 19 for individuals with 1-6 years of education and 24 for individuals with 7 or more years of education as previously described. ${ }^{7}$ The total scores of MMSE was 30, and the cut-off scores for screening MCI were as follows: 19 for illiterate individuals; 22 for individuals with 1-6 years of education; and 26 for individuals with 7 or more years of education. These criteria we followed have been proven to be appropriate for screening MCI in elderly Chinese people in a large cohort-based study. ${ }^{17}$ The screening of MCI in the present study was a combination of these two methods with the following criteria: MoCA $\leq 13$ and MMSE $\geq 20$ for illiteracy; MoCA $\leq 19$ and MMSE $\geq 23$ for participants with 1-6 years of education; and MoCA $\leq 24$ and MMSE $\geq 27$ for participants with $\geq 7$ years of education.

\section{STATISTICAL ANALYSIS}

Statistical analyses were performed using the SPSS 17.0 software (SPSS Inc., Chicago, IL, USA). Data was tested for normality distribution by visual inspection of histograms and the Shapiro- Wilk W-test. Continuous variables were presented as mean $\pm \mathrm{SD}$ or median $(\mathrm{Q})$, and categorical variables were described as frequencies (percentage). Logistic regression analysis was used to compare the demographic characteristics, lifestyle, and physical and laboratory parameters between participants with and without MCI. The analysis of variance (ANOVA) and rank sum test for continuous variables and CochranMantel- Haenszel $\chi$ test for categorical variables were used to compare the demographic characteristics, lifestyle, physical and laboratory parameters, and macronutrients' intake among different quartiles of \% fat/ energy (percentage of energy from total fat). Multivariate logistic regression was used to identify the potential risk factors of MCI and to estimate the risk of MCI between different quartiles of \% nutrients/energy (percentage of energy from each nutrient). All statistical analyses were performed with a two-tailed alpha level of 0.05 .

\section{RESULTS}

\section{Demographic and physical characteristics of participants}

A total of 661 participants were included in this study. The demographic and physical characteristics, lifestyle and laboratory parameters and their association with MCI are presented in table 1 . Of all the participants, 303 $(45.8 \%)$ were males and $358(54.2 \%)$ were females: the average age was $48.5 \pm 7.3$ years (30-64 years); the average BMI was $26.2 \pm 3.6 \mathrm{~kg} / \mathrm{m}^{2}$; the overweight and obese group included $310(46.9 \%)$ and $104(15.7 \%)$, respectively; 80 (12.1\%) participants had MCI; and the other 581 participants $(87.9 \%)$ had normal cognitive functions. Increased age and BMI, and the presence of hypertension and hyperlipidaemia were associated with the greater prevalence of
MCI, while educational level was negatively correlated with the prevalence of MCI. However, other factors such as gender, race/ethnicity, labour intensity, aerobic exercise, smoking, drinking, and diabetic and hypertension status were not associated with the prevalence of MCI (table 1).

We next compared the demographic characteristics, lifestyle, physical and laboratory parameters, and energy intake from each macronutrient across quartiles of \% fat/ energy (percentage of energy from total fat). As shown in table 2, participants in higher \% fat/energy quartiles had shown increased frequency of MCI, with diabetes and hyperlipidaemia at more advanced age. Lifestyle (smoking, drinking and exercise) and BMI were not significantly different across quartiles of $\%$ fat/energy. The total energy intake in the highest \% fat/energy quartile was higher than that in the lowest quartile, but lower than that in the third \% fat/energy quartile. Intake of protein and dietary fibre (in term of $\mathrm{g} /$ day or $\%$ of total energy) was increased across increasing \% fat/energy quartiles, while the intake of carbohydrates was decreased as quartiles of $\%$ fat/energy rose. These data suggested that the increased dietary intake of fat might be associated with the development of MCI.

Before analysis of the relationship between macronutrients' intake and cognitive function, a multivariate logistic regression analysis was employed to identify the association of BMI, age, education, hypertension, hyperlipidaemia, diabetes and energy intake with MCI. In this assay, MCI status was defined as the dependent variable, while BMI, age, education, hypertension, hyperlipidaemia, diabetes and energy intake were set as the independent variables. As shown in table 3, age (OR 1.72, 95\% CI 1.18 to 2.52 ), hyperlipidaemia (OR 2.46, 95\% CI 1.48 to 4.10 ) and total energy intake (OR $1.67,95 \%$ CI 1.31 to 2.12) were positively associated with the risk for MCI, while education (OR $0.54,95 \%$ CI 0.31 to 0.94 ) was a protective factor for MCI. Although BMI was not significantly associated with the risk for MCI, a trend exhibiting increased risk of MCI was observed in participants with higher BMI (OR 1.36, 95\% CI 0.95 to 1.96 ).

We then explored the association of \% of energy from a specific macronutrient (carbohydrates, fat and protein) on the prevalence of MCI, with their age, BMI, education, energy (quartiles) and hyperlipidaemia. The risk of MCI was reduced by about $70 \%$ in the highest quartile of the \% carbohydrate/energy group. On the contrary, the risk for MCI was increased to nearly 2.48- and 2.77fold in the third and the highest quartile of \% protein/ energy, respectively. To be consistent, the risk for MCI was elevated to around 3.36- and 3.90-fold in the third and the highest quartile of \% fat/energy, respectively (table 4).

\section{DISCUSSION}

This study involving a young and middle-age group population showed that a higher $\%$ fat/energy and $\%$ protein/energy intakes were associated with an increased 
Open Access

Table $1 \mathrm{MCl}$ by different groups of characteristics

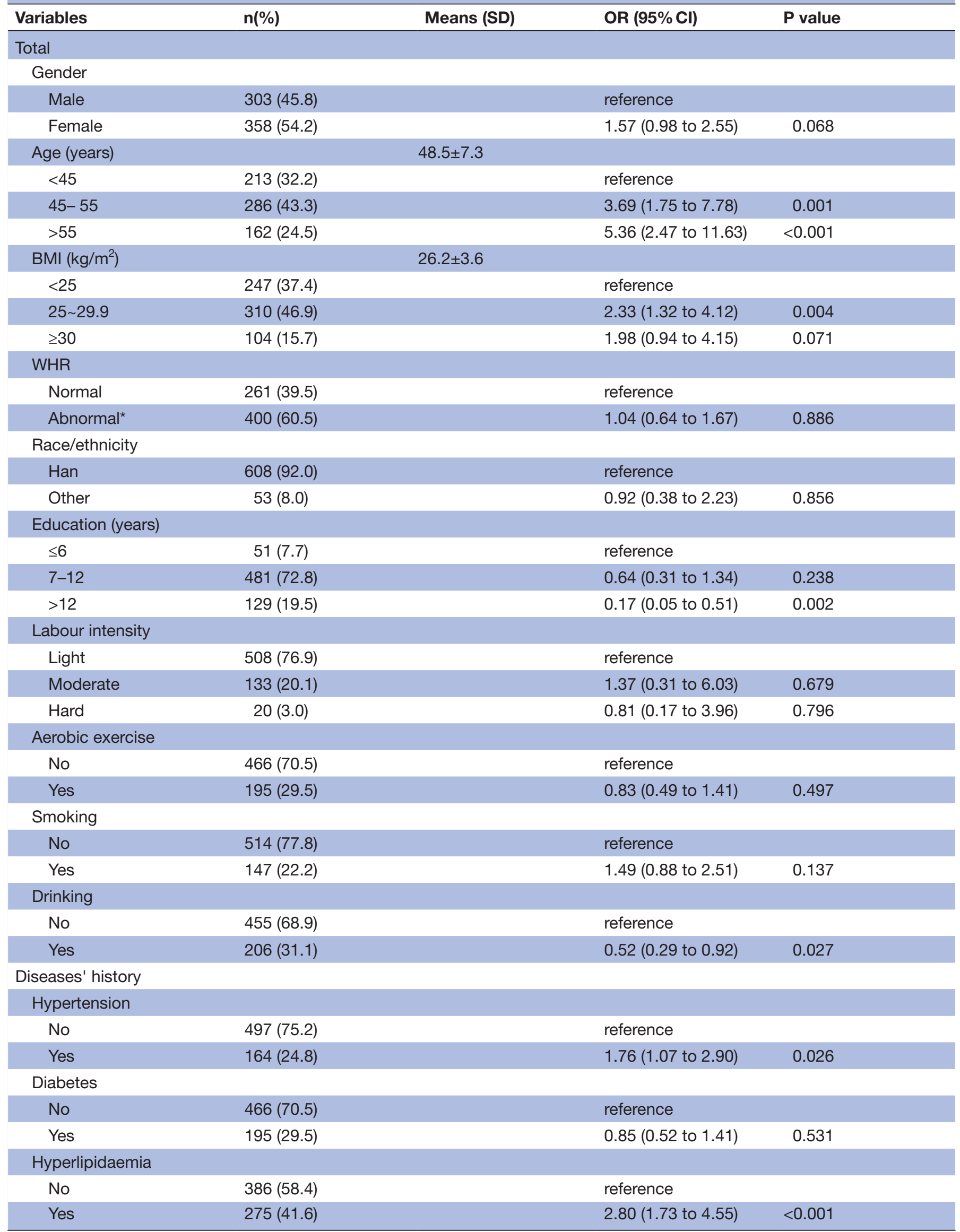


Table 1 Continued

\begin{tabular}{|c|c|c|c|c|}
\hline Variables & $n(\%)$ & Means (SD) & OR $(95 \% \mathrm{Cl})$ & $P$ value \\
\hline \multicolumn{5}{|l|}{$\mathrm{MCl}$} \\
\hline No & 581 (87.9) & & & \\
\hline
\end{tabular}

${ }^{*}$ WHR $>0.8$ for female, WHR $>0.9$ for male.

$\mathrm{BMI}$, body mass index; $\mathrm{MCl}$, mild cognitive impairment; WHR, waist-to-hip ratio.

prevalence of MCI. In contrast, a high \% carbohydrate/ energy intake was correlated with a reduced risk of MCI. These findings suggested that a dietary pattern of high fat and protein intake, and a low carbohydrate intake might have adverse effects on the development of MCI. Therefore, a balanced dietary pattern that consists of optimal fat, protein and carbohydrate proportions may be beneficial in maintaining normal cognitive function in this population.

Our findings were contrary to the results of a study by Robert et al, which reported that diet with a relatively high-calorific intake from carbohydrates and a low- calorific intake from fat and proteins might increase the risk of MCI. ${ }^{9}$ This inconsistency may stem from the difference in the age of participants and the differential source of carbohydrate in their diets. In the present study, the participants were relatively younger than the participants in the study by Robert et al ( $<65$ years VS $70-89$ years). ${ }^{9}$ In addition, Chinese diets are rich in starchy foods (eg, refined grain, tubers and their products), which might represent the main source of dietary energy, while carbohydrates in Robert et $a l$ s study were mainly derived from simple sugars. ${ }^{9}$ As we know, elderly persons having a dietary pattern high in

Table 2 Characteristics of participants by \% fat intake quartiles of \% fat of total energy

\begin{tabular}{|c|c|c|c|c|c|}
\hline \multirow[b]{3}{*}{ Variable } & Q1 & Q2 & Q3 & Q4 & \\
\hline & $<20 \%$ & $20 \%-28 \%$ & 29-35 & $>35 \%$ & \\
\hline & $n=165$ & $n=165$ & $n=165$ & $n=165$ & $P$ value \\
\hline \multicolumn{6}{|l|}{$\mathrm{N}(\%)$} \\
\hline Female & 95 (57.6) & 88 (53.3) & $93(56.4)$ & $82(49.4)$ & 0.447 \\
\hline Diabetes & $42(25.5)$ & 55 (33.3) & $43(26.1)$ & $55(33.1)$ & $<0.001$ \\
\hline Hypertension & $41(24.8)$ & $32(19.4)$ & $44(26.7)$ & 47 (28.3) & 0.262 \\
\hline Hyperlipidaemia & $46(27.9)$ & $73(44.2)$ & $76(46.1)$ & 80 (48.2) & $<0.001$ \\
\hline Drinking & 56 (33.9) & $47(28.5)$ & $50(30.3)$ & 53 (31.9) & 0.742 \\
\hline Smoking & 34 (20.6) & $32(19.4)$ & $38(23)$ & $43(25.9)$ & 0.198 \\
\hline Aerobic exercise & $43(26.1)$ & $52(31.5)$ & $54(32.7)$ & $46(27.7)$ & 0.504 \\
\hline Education ( $>12$ years) & $33(20.0)$ & $41(24.8)$ & $31(18.8)$ & $24(14.5)$ & 0.123 \\
\hline $\mathrm{MCl}$ & $6(3.6)$ & $14(8.5)$ & $28(17.0)$ & $32(19.3)$ & $<0.001$ \\
\hline \multicolumn{6}{|l|}{ Mean(SD) } \\
\hline Age (year) & $47.4(6.9)$ & $47.5(7.3)$ & $49.1(7.5)$ & $50.2(6.9)$ & $<0.001$ \\
\hline $\mathrm{BMI}\left(\mathrm{kg} / \mathrm{m}^{2}\right)$ & $26.1(3.4)$ & $26.1(3.6)$ & $26.5(3.5)$ & $26.2(3.9)$ & 0.712 \\
\hline WHR & $0.89(0.08)$ & $0.89(0.08)$ & $0.89(0.07)$ & $0.89(0.06)$ & 0.903 \\
\hline Total energy & $1830(612)$ & $1815(675)$ & $2365(871)$ & $2197(735)$ & $<0.001$ \\
\hline \multicolumn{6}{|l|}{ Intake (\% of energy) } \\
\hline$\%$ carbohydrates & $68(5)$ & $59(4)$ & $51(3)$ & $38(7)$ & $<0.001$ \\
\hline$\%$ protein & $16(3)$ & $17(3)$ & $17(2)$ & $18(4)$ & $<0.001$ \\
\hline \multicolumn{6}{|c|}{ Intake (g/d) median (Q75-Q25) } \\
\hline Carbohydrates & $278(170)$ & $252(215)$ & $291(141)$ & $200(131)$ & $<0.001$ \\
\hline Protein & $62(37)$ & $74(40)$ & $97(58)$ & $96(51)$ & $<0.001$ \\
\hline Fat & $28(15)$ & $47(24)$ & $76(49)$ & $103(63)$ & $<0.001$ \\
\hline Fibre & $10(9.2)$ & $12(9.1)$ & $15(8.3)$ & $14(10.6)$ & $<0.001$ \\
\hline
\end{tabular}

BMI, body mass index; $\mathrm{MCl}$, mild cognitive impairment; Q, quartiles; WHR, waist-to-hip ratio. 


\begin{tabular}{|c|c|c|c|c|}
\hline Variable & wald & OR & $95 \% \mathrm{Cl}$ & $\mathbf{P}$ \\
\hline $\mathrm{BMI}^{*}$ & 2.828 & 1.36 & 0.95 to 1.96 & 0.09 \\
\hline Age $^{*}$ & 7.846 & 1.72 & 1.18 to 2.52 & 0.005 \\
\hline Hypertension & 0.257 & 1.15 & 0.62 to 2.02 & 0.61 \\
\hline Hyperlipidaemia & 12.071 & 2.46 & 1.48 to 4.10 & 0.001 \\
\hline Diabetes & 0.308 & 1.17 & 0.68 to 2.02 & 0.58 \\
\hline Education* & 4.677 & 0.54 & 0.31 to 0.94 & 0.031 \\
\hline Energy (quartiles) & 17.251 & 1.67 & 1.31 to 2.12 & $<0.001$ \\
\hline
\end{tabular}

*Processing as classification variables,BMl $(<25,25-29.9, \geq 30)$, age $(<45,45-55,>55)$, education $(\leq 6,6-12,>12)$.

$\mathrm{BMI}$, body mass index; $\mathrm{MCl}$, mild cognitive impairment.

simple sugars may often disrupt their normal glucose and insulin metabolism. ${ }^{18-21}$ Glucose and insulin metabolism has been shown to have a close relationship with cognitive functions. ${ }^{22}$ Therefore, we hypothesised that in the study by Robert $e t$ al, a high level of simple sugar intake was a potential risk factor of MCI in the elders (median age $=79.5$ years $).{ }^{9}$ In our study, the participants were much younger (48.5 \pm 7.3 years) and obtained carbohydrates

\begin{tabular}{|c|c|c|c|c|}
\hline Variable & $\begin{array}{l}\text { Cutpoint } \\
\text { (\%) }\end{array}$ & $\begin{array}{l}\text { Incident } \\
\text { MCI, n(\%) }\end{array}$ & $\begin{array}{l}\text { OR } \\
(95 \% \mathrm{Cl})^{*}\end{array}$ & $\mathbf{P}$ \\
\hline \multicolumn{5}{|c|}{ Carbohydrate } \\
\hline Q1 & $<46$ & $33(20.0)$ & reference & \\
\hline Q2 & $47-54$ & $25(15.2)$ & $\begin{array}{l}0.77(0.42 \\
\text { to } 1.41)\end{array}$ & 0.39 \\
\hline Q3 & $55-63$ & $15(9.1)$ & $\begin{array}{l}0.58(0.29 \\
\text { to } 1.16)\end{array}$ & 0.12 \\
\hline Q4 & $>63$ & $7(4.2)$ & $\begin{array}{l}0.30(0.12 \\
\text { to } 0.72)\end{array}$ & 0.007 \\
\hline
\end{tabular}

\begin{tabular}{|c|c|c|c|c|}
\hline \multicolumn{5}{|c|}{ Protein } \\
\hline Q1 & $<14.9$ & $10(6.1)$ & reference & \\
\hline Q2 & $15.0-16.5$ & $20(12.1)$ & $\begin{array}{l}1.70(0.74 \\
\text { to } 3.93)\end{array}$ & 0.21 \\
\hline Q3 & $16.6-18.5$ & 23 (13.9) & $\begin{array}{l}2.48(1.09 \\
\text { to } 5.61)\end{array}$ & 0.03 \\
\hline Q4 & $>18.5$ & 27 (16.3) & $\begin{array}{l}2.77(1.24 \\
\text { to } 6.15)\end{array}$ & 0.01 \\
\hline \multicolumn{5}{|l|}{ Fat } \\
\hline Q1 & $<20$ & $6(3.6)$ & reference & \\
\hline Q2 & $21-28$ & $14(8.5)$ & $\begin{array}{l}2.22(0.81 \\
\text { to } 6.10)\end{array}$ & 0.12 \\
\hline Q3 & 29-35 & $28(17.0)$ & $\begin{array}{l}3.36(1.30 \\
\text { to } 8.67)\end{array}$ & 0.01 \\
\hline Q4 & $>35$ & 32 (19.3) & $\begin{array}{l}3.90(1.53 \\
\text { to } 9.89)\end{array}$ & 0.004 \\
\hline
\end{tabular}

*Adjusted for age, BMI, education, energy (quartiles), hyperlipidaemia.

$\mathrm{BMI}$, body mass index; $\mathrm{MCl}$, mild cognitive impairment. mainly from starchy foods, thus their risk of abnormal blood glucose level and insulin metabolism was minimal and they consequently showed a lower prevalence of MCI. Collectively, we speculated that intake of high fat instead of high carbohydrates might represent a key dietary factor for increased risk of MCI in younger population.

The association between fat intake and MCI has been well established by conducting a series of human and rodent studies. A randomly controlled clinical trial has shown that attention, speed and mood were impaired in a cohort of young males (aged $22 \pm 1$ years) subjected to high-fat, low-carbohydrate diets for 5 days ${ }^{23}$ suggesting that a high-fat diet was potentially detrimental to the brain in healthy participants. Edwards et al had demonstrated that consumption of a high-fat diet led to increased simple reaction time and decreased power of attention. ${ }^{24}$ Moreover, in animal studies, rats fed with long-term high-fat diet developed hippocampal microvascular insulin resistance and significantly declined cognitive function in the two-trial spontaneous alternation behaviour test and the novel object recognition test. ${ }^{25}$ In addition, a high-fat diet (40\% energy from fat) had shown to induce biochemical changes (increased amyloid beta deposition and neurofibrillary tangle formation) and decreased synaptic plasticity in the brain of mice. ${ }^{2526}$

As suggested by the human and animal studies, the effect of high-fat intake on MCI might have resulted due to insulin resistance (IR). A high-fat diet is regarded as a well-established approach to induce IR in peripheral organs and hypothalamus. ${ }^{26}{ }^{27}$ Accumulating evidence has shown that a high-fat diet could cause increased blood glucose levels and free fatty acid (FFA) concentrations, ${ }^{28}$ and subsequent insulin insensitivity. However, the relationship between cognitive function and insulin sensitivity/resistance has been well established by conducting many studies. ${ }^{29-32}$ Therefore, we assumed that a similar mechanism might have accounted for the increased risk of MCI caused by high-fat intake in this present study. We also found that hyperlipidaemia (hypercholesterolaemia and/or hypertriglyceridaemia) was associated with the risk for developing MCI. But the relationship among hyperlipidaemia, increased fat intake and cognitive impairment is still unclear. A systematic review and meta-analysis ${ }^{33}$ showed that the reduction in triglyceride levels was more distinct in the high-fat diet groups. Holloway et $a l^{23}$ have reported that there is no significant difference in cholesterol concentrations between high-fat diet and standard diet groups. Thus hyperlipidaemia was not necessarily a result of high-fat intake, and it might be independent of the high-fat diet-induced risk of MCI.

Interestingly, we have noticed that the prevalence of MCI was higher as the protein intake was increased (table 4). In China, during recent years, the intake of dietary protein among the population has increased, and the main sources of protein have changed from vegetable proteins to animal proteins, in particular the red meats. ${ }^{34}$ We speculated that, when protein accounts for only $15.0 \%$ to $16.5 \%$ of total energy, the protein intake might not show any significant 
association with the incidence of MCI. Moreover, it suggests that an appropriate protein intake is critical for maintaining normal cognitive functions and that over-consumption of protein might be harmful to cognition. However, the appropriate protein intake for optimal cognitive functions and the ways to delay the decline in cognition with advanced age remained unknown. ${ }^{35}$

In addition to macronutrients' intake, we identified other potential risk factors for the development of MCI in this study, including age, education, hyperlipidaemia and total energy intake. Ageing has been associated with an increased risk of cardiovascular diseases and Alzheimer's disease, which is manifested by reduced cognitive function, neuro-degeneration and the onset of dementia. ${ }^{36}$ Consistent with a previous study, advanced age was associated with a decline in cognitive function in the present study. Moreover, we found that hyperlipidaemia was associated with significantly increased risk of MCI (OR 2.46, $\mathrm{P}<0.01)$, as reported by other studies. ${ }^{37} 38$ Educational attainment is a key component of successful maintenance of cognitive function in old people, and thus serves as a major protective factor for dementia. ${ }^{39}$ Consistently, we found that higher educational level was potentially a protective factor against MCI in this study. In addition to these demographic characteristics, we also discovered that a high total energy intake was significantly correlated with increased risk of MCI. Consequent with an energy intake increase during each quartile, the risk of MCI was increased by around 1.66-fold (table 3). However, this increased risk was not associated with overweight and obesity, since we did not find any significant difference in BMI and WHR among energy intake quartiles. Moreover, after adjustment for energy intake, the results demonstrated that high fat and protein intake was associated with increased risk of MCI (table 4).

There were some limitations to this study. First, being a retrospective study, recall bias in reporting of dietary nutrients could not be excluded, especially for those with cognitive impairment. To effectively minimise the potential recall bias, we used special model and measuring rulers or cups to help in quantifying the consumed food. Second, as the participants were recruited at community hospitals, the study exhibited a potential risk for participation bias. Moreover, the higher frequencies of vascular disease risk factors (such as diabetes, hypertension and hyperlipidaemia) in participants, might introduce bias towards the association between dietary nutrients' intake and cognitive function. Third, hypertension and diabetes were self-reported, which might introduce information bias. Finally, the participants were recruited only from Beijing, and any generalisation of the results of this study to other locations and to other ethnicities should be performed with caution.

In summary, after adjustment for age, education, hyperlipidaemia and total energy intake, high-fat and protein intake and low-carbohydrate intake were associated with greater risk for MCI. A balanced dietary pattern consisting of optimal fat, protein and carbohydrate ratio may be potentially beneficial to the maintenance of normal cognitive functions in young and middle-aged people.
Contributors WWM and RX conceived and designed the study, YZ and BJD collected the data, BJD performed the statistical analyses and drafted the manuscript, LZ drafted and revised the manuscript and YXB helped in collection and analysis of the data. All authors read and approved the final manuscript.

Funding The research was supported by the National Natural Science Foundation of China (Grant No. 81472982 and 81773406), Support Project of High-level Teachers in Beijing Municipal Universities in the Period of 13th Five-year Plan (grant No.CIT\&TCD201704096) and Scientific Research Common Program of Beijing Municipal Commission of Education (grant No.KM201710025007).

Competing interests None declared.

Patient consent Obtained.

Ethics approval All experimental procedures were conducted in accordance with the guidelines in the Declaration of Helsinki and approved by the Ethics Committee of Capital Medical University, Beijing(No.2014SY33).

Provenance and peer review Not commissioned; externally peer reviewed.

Data sharing statement The materials and datasets used and/or analysed during the current study are available from the corresponding author on reasonable request.

Open Access This is an Open Access article distributed in accordance with the Creative Commons Attribution Non Commercial (CC BY-NC 4.0) license, which permits others to distribute, remix, adapt, build upon this work non-commercially, and license their derivative works on different terms, provided the original work is properly cited and the use is non-commercial. See: http://creativecommons.org/ licenses/by-nc/4.0/

(c) Article author(s) (or their employer(s) unless otherwise stated in the text of the article) 2018. All rights reserved. No commercial use is permitted unless otherwise expressly granted.

\section{REFERENCES}

1. Zhao X, Yuan L, Feng L, et al. Association of dietary intake and lifestyle pattern with mild cognitive impairment in the elderly. J Nutr Health Aging 2015;19:164-8.

2. Kim J, Yu A, Choi BY, et al. Dietary patterns derived by cluster analysis are associated with cognitive function among Korean older adults. Nutrients 2015;7:4154-69.

3. Petersson SD, Philippou E. Mediterranean diet, cognitive function, and dementia: a systematic review of the evidence. Adv Nutr 2016;7:889-904.

4. Huhn S, Kharabian Masouleh S, Stumvoll M, et al. Components of a Mediterranean diet and their impact on cognitive functions in aging. Front Aging Neurosci 2015;7:132.

5. Dong L, Xiao R, Cai C, et al. Diet, lifestyle and cognitive function in old Chinese adults. Arch Gerontol Geriatr 2016;63:36-42.

6. Beilharz JE, Maniam J, Morris MJ. Diet-induced cognitive deficits: the role of fat and sugar, potential mechanisms and nutritional interventions. Nutrients 2015;7:6719-38.

7. Lu Y, An Y, Guo J, et al. Dietary intake of nutrients and lifestyle affect the risk of mild cognitive impairment in the Chinese elderly population: a cross-sectional study. Front Behav Neurosci 2016;10:229.

8. Creavin ST, Gallacher J, Pickering J, et al. High caloric intake, poor cognition and dementia: the Caerphilly prospective study. Eur $J$ Epidemiol 2012;27:197-203.

9. Roberts RO, Roberts LA, Geda YE, et al. Relative intake of macronutrients impacts risk of mild cognitive impairment or dementia. J Alzheimers Dis 2012;32:329-39.

10. WHO Expert Consultation. Appropriate body-mass index for Asian populations and its implications for policy and intervention strategies. Lancet 2004;363:157-63.

11. Zheng JS, Wang L, Lin $M$, et al. BMI status influences the response of insulin sensitivity to diacylglycerol oil in Chinese type 2 diabetic patients. Asia Pac J Clin Nutr 2015;24:65-72.

12. Sharp ES, Gatz M. Relationship between education and dementia: an updated systematic review. Alzheimer Dis Assoc Disord 2011;25:289-304.

13. The Chinses Nutrion Society. Chinese residents dietary guidelines. Beijing: People's Medical Publishing House, 2016:332-3.

14. Young J, Angevaren M, Rusted J, et al. Aerobic exercise to improve cognitive function in older people without known cognitive impairment. Cochrane Database Syst Rev 2015;4:D5381. 
15. Block G, Thompson FE, Hartman AM, et al. Comparison of two dietary questionnaires validated against multiple dietary records collected during a 1-year period. J Am Diet Assoc 1992;92:686-93.

16. Yang YX, Wang G, Pan X. China food composition. Beijing: Peking University Medical Press, 2009.

17. Lu J, Li D, Li F, et al. Montreal cognitive assessment in detecting cognitive impairment in Chinese elderly individuals: a populationbased study. J Geriatr Psychiatry Neurol 2011;24:184-90.

18. Witte AV, Fobker M, Gellner R, et al. Caloric restriction improves memory in elderly humans. Proc Natl Acad Sci U S A 2009;106:1255-60.

19. Malik VS, Popkin BM, Bray GA, et al. Sugar-sweetened beverages and risk of metabolic syndrome and type 2 diabetes: a metaanalysis. Diabetes Care 2010;33:2477-83.

20. S Roriz-Filho J, Sá-Roriz TM, Rosset I, et al. (Pre)diabetes, brain aging, and cognition. Biochim Biophys Acta 2009;1792:432-43.

21. Vanhanen M, Koivisto K, Kuusisto J, et al. Cognitive function in an elderly population with persistent impaired glucose tolerance. Diabetes Care 1998;21:398-402.

22. Maggio M, Dall'Aglio E, Lauretani F, et al. The hormonal pathway to cognitive impairment in older men. $J$ Nutr Health Aging 2012;16:40-54

23. Holloway CJ, Cochlin LE, Emmanuel Y, et al. A high-fat diet impairs cardiac high-energy phosphate metabolism and cognitive function in healthy human subjects. Am J Clin Nutr 2011;93:748-55.

24. Edwards LM, Murray AJ, Holloway CJ, et al. Short-term consumption of a high-fat diet impairs whole-body efficiency and cognitive function in sedentary men. Faseb $J$ 2011;25:1088-96.

25. Fu Z, Wu J, Nesil T, et al. Long-term high-fat diet induces hippocampal microvascular insulin resistance and cognitive dysfunction. Am J Physiol Endocrinol Metab 2017;312:E89-97.

26. Kothari $\mathrm{V}$, Luo $\mathrm{Y}$, Tornabene $\mathrm{T}$, et al. High fat diet induces brain insulin resistance and cognitive impairment in mice. Biochim Biophys Acta 2017; 1863:499-508.
27. Liu Z, Patil IY, Jiang T, et al. High-fat diet induces hepatic insulin resistance and impairment of synaptic plasticity. PLoS One 2015;10:e128274.

28. Hernandez TL, Sutherland JP, Wolfe P, et al. Lack of suppression of circulating free fatty acids and hypercholesterolemia during weight loss on a high-fat, low-carbohydrate diet. Am J Clin Nutr 2010;91:578-85.

29. Cholerton B, Baker LD, Craft S. Insulin, cognition, and dementia. Eur $J$ Pharmacol 2013;719(1-3):170-9.

30. Sasaoka T, Wada T, Tsuneki H. Insulin resistance and cognitive function. Nihon Rinsho 2014;72:633-40.

31. Kullmann S, Heni M, Hallschmid M, et al. Brain insulin resistance at the crossroads of metabolic and cognitive disorders in humans. Physiol Rev 2016;96:1169-209.

32. Cetinkalp S, Simsir IY, Ertek S. Insulin resistance in brain and possible therapeutic approaches. Curr Vasc Pharmacol 2014;12:553-64.

33. Schwingshackl L, Hoffmann G. Comparison of effects of long-term low-fat vs high-fat diets on blood lipid levels in overweight or obese patients: a systematic review and meta-analysis. J Acad Nutr Diet 2013;113:1640-61.

34. The Chinses Nutrion Society. Chinese residents dietary guidelines. Beijing: People's Medical Publishing House, 2016:93-4.

35. Koh F, Charlton K, Walton K, et al. Role of dietary protein and thiamine intakes on cognitive function in healthy older people: a systematic review. Nutrients 2015;7:2415-39.

36. Barnes JN. Exercise, cognitive function, and aging. Adv Physiol Educ 2015;39:55-62.

37. Carlsson CM, Nondahl DM, Klein BE, et al. Increased atherogenic lipoproteins are associated with cognitive impairment: effects of statins and subclinical atherosclerosis. Alzheimer Dis Assoc Disord 2009;23:11-17.

38. Yagi S, Akaike M, Aihara K, et al. High plasma aldosterone concentration is a novel risk factor of cognitive impairment in patients with hypertension. Hypertens Res 2011;34:74-8.

39. Stern Y. Cognitive reserve. Neuropsychologia 2009;47:2015-28. 